\title{
Necroptosis: a regulated inflammatory mode of cell death
}

\author{
Yogesh K. Dhuriya ${ }^{1,2}$ and Divakar Sharma ${ }^{3,4^{*}}$ (D)
}

\begin{abstract}
Programmed cell death has a vital role in embryonic development and tissue homeostasis. Necroptosis is an alternative mode of regulated cell death mimicking features of apoptosis and necrosis. Necroptosis requires protein RIPK3 (previously well recognized as regulator of inflammation, cell survival, and disease) and its substrate MLKL, the crucial players of this pathway. Necroptosis is induced by toll-like receptor, death receptor, interferon, and some other mediators. Shreds of evidence based on a mouse model reveals that deregulation of necroptosis has been found to be associated with pathological conditions like cancer, neurodegenerative diseases, and inflammatory diseases. In this timeline article, we are discussing the molecular mechanisms of necroptosis and its relevance to diseases.
\end{abstract}

Keywords: Necroptosis, Inflammation, Neurodegenerative disease, RIPK3, MLKL

\section{Background}

Cell demise and its survival are the fundamental features of metazoans to maintain the tissue homeostasis. On morphological basis, cell death is achieved by apoptosis, necrosis, and autophagy [1]. A plethora of studies has been performed on apoptosis and autophagy which reveals a clear picture of molecular mechanisms of apoptosis and autophagy and is recognized as a highly regulated process. Hence, apoptosis and autophagy are regarded as "programmed cell death" while necrosis is considered as "unprogrammed" due to deregulated activity. Decades ago, a novel type of cell death was reported where apoptotic pathway was inhibited, which exhibited morphological features of both apoptosis and necrosis and hence was termed as necroptosis [2]. Interestingly, necroptosis is inhibited by Necrostatin-1 (Nec-1) by inhibiting the activity of receptor-interacting protein kinase 1 (RIPK1), which suggests that it is a well-regulated process or programmed necrosis. Later studies on morphological features of necroptosis confirmed that it is the unregulated necrotic death, stimulated by the secretion of cytokines/chemokines resulting in inflammation [3]. Inflammation involves a series of reactions in

\footnotetext{
*Correspondence: divakarsharma88@gmail.com

${ }^{3}$ Department of Biochemistry, National JALMA Institute for Leprosy and Other Mycobacterial Diseases, Tajganj, Agra, India

${ }^{4}$ Interdisciplinary Biotechnology Unit, Aligarh Muslim University, Aligarh 202002, India

Full list of author information is available at the end of the article
}

response to pathogen-infected cells resulting in the elimination of infected cells as well as wound healing.

Necroptosis is a regulated necrosis mediated by death receptors [4]. This form of necrosis works against pathogen-mediated infections, morphologically characterized by cell swelling followed by rupturing of plasma membrane. It is well known that involvement of receptor like Fas, TNF, and TRAIL can lead to cell death through the recruitment of caspase- 8 leading to initiation of extrinsic apoptotic pathway [5]. A plethora of evidences has shown that inhibition of caspase- 8 molecule shift extrinsic apoptosis to necrosis mode of cell death due to activation of RIPK3 and MLKL [6-10]. Hence, it is an alternative mode of cell death when caspase-8-dependent apoptotic pathway is blocked. Initiation of necroptosis is mediated by immune ligands including Fas, TNF, and LPS leading to activation of RIPK3 which further activates the MLKL by phosphorylation [10]. Phosphorylated MLKL translocates into the inner leaflet of the plasma membrane and disturbs the integrity of the cell [11-13]. Although RIPK3 and MLKL is necessary for programmed cell death $[10,14,15]$, necroptosis is confined to certain types of tissue that express RIPK3/MLKL. In normal circumstances, caspase-8 molecule activates apoptosis by blocking the necroptosis and by cleaving RIPK1 and CYLD [16-18]. Classical necrosis leads to increased secretion of cytokines and decreased secretion of damaged associated molecular 
pattern (DAMP-endogenous molecules released in response to tissue damage) in contrast to necroptosis. Tumor necrosis factor (TNF) promotes the inflammatory cytokine synthesis in most of cell types resulting in various inflammatory diseases like Crohn's disease, psoriasis, bowel disease, and rheumatoid arthritis [19, 20] and regulates production of chemokines and cytokines as primary outcomes of TNF stimulation [21]. Shifting of TNF-mediated response into programmed necrosis is not simply shifting of inflammation to necroptosis; it represents shifting of robust inflammatory response into necroptosis which terminates earlier in contrast to classical pro-inflammatory response. There are two basic conditions for necroptosis: (1) cells must express RIPK3 and (2) inhibition of caspase-8 molecule. Recent study of Moriwaki and Chan [22] has shown that MLKL rather than RIPK3 decides whether cell undergoes apoptosis or necroptosis which further suggests that expression of MLKL is necessary for induction of necroptosis using RIPK3 T231A/S232A mutant-expressing cells. Numerous in vitro studies have reported that inhibition of caspase- 8 molecules resulted in activation of RIPK3, a key player of necroptosis [6, 7, 23]. Duprez et al. [24] have shown that caspase- 8 inhibition might not always be mandatory to trigger the in vivo necroptosis.

\section{Molecular mechanism of necroptosis}

Recent studies have been focused on TNF $\alpha$, RIPK3, and caspase- 8 to understand the molecular mechanism of necroptosis. Necroptosis can be initiated by TNF superfamily receptors, toll-like receptors (TLR3 and TLR4), and interferon receptors while TNFR1-mediated necroptosis is well characterized. Base on the driving factors, necroptosis is classified into three categories: (1) Extrinsic necroptosis is stimulated by TNF $\alpha$, (2) Intrinsic necroptosis is stimulated by reactive oxygen species (ROS), and (3) Ischemia mediated intrinsic necroptosis. TNF $\alpha$-mediated necroptosis is a classical necroptosis which binds with complementary receptor leading to formation of short-lived membrane signaling complex (known as complex I) containing TRADD, FADD, RIPK1, TRAF2/TRAF5, and cIAP1/CIAP2. TRADD is an adaptor molecule recruit RIPK1 to TNFR1 $[25,26]$. Subsequently, cIAPs and TRAF2/3/5 are recruited to complex I [27]. On activation, cIAP $1 / 2$ and TRAF $2 / 5$ mediate ubiquitination of RIPK1 which resulted in formation of stable complex I and initiate alternative pathway that culminates with cell survival pathway including NF-кB- and MAPK-mediated pathway [28]. NF-кB signaling plays a key role in counteracting the cytotoxic effect of TNFo, and prosurvival effect of NF- $\mathrm{KB}$ is mediated by cIAP1/2 and cFLIP $_{\mathrm{L}}$ (cellular FLICE-like inhibitory protein) $[29,30]$. Hence, complex I is a crucial checkpoint for cell survival and necroptosis [31].
Normally, apoptosis is inhibited by formation of a heterodimer of caspase- 8 and $\mathrm{CFLIP}_{\mathrm{L}}$ leading to inactivation of caspase-8. Caspase- 8 induces the exogenous apoptosis and deactivates the necroptosis by inhibiting the activity of RIPK3 and RIPK1. Elimination or inhibition of caspase-8 leads to activation of RIPK1 through deubiquitination mediated by cylindromatosis (CYLD) $[16,32]$ thus destabilizing the complex I. Removal of ubiquitin chain from RIPK1 leads to its interaction with FADD, TRADD, RIPK3, and caspase- 8 which further resulted in formation of complex II. RIPK1 interacts with RIPK3 through receptor homology domain (RHD) leading to formation of necrosome which further initiates the downstream signaling resulting in necroptosis [33]. Although both RIPK3 and RIPK1 are necessary for induction of necroptosis, RIPK3 can alone promote necroptosis when it is overexpressed in cells [34]. On activation, RIPK3 phosphorylates the pseudokinase MLKL (mixed lineage kinase domain-like protein) which plays a key role in induction of necroptosis. MLKL acts in two ways: (1) either it acts as platform in plasma membrane for recruitment of $\mathrm{Na}^{+}$ion or $\mathrm{Ca}^{++}$channels or (2) promotes the pore formation in plasma membrane by interacting with amino terminal of phosphotidyl inositol phosphate (Fig. 1) [10, 35]. Wang et al. [36] reported the role of mitochondrial molecule PGAM (phosphatase phosphoglycerate mutase) -5 in necroptosis while the role of PGAM-5 is still controversial as many studies have shown that even complete depletion of the mitochondria did not influence the necroptosis processes [37].

\section{Non-classical necrosome}

In classical necroptosis, necrosome complex is formed due to interaction between RIPK3 and RIPK1 through the RHIM domain. Phosphorylation of these proteins at their kinase domain promotes RHIM-mediated interactions of both proteins which results in formation of amyloid-like filamentous signaling complex [38, 39] and culminates with necroptosis. In spite of these proteins, many other proteins like TLR3/4, TRIF, and DAI (DNA activator of interferon) also have RHIM domain; hence, they can also form the necrosome which is considered as non-classical necrosome. Further, proteins sharing the RHIM domain may share functions in cell death signaling, innate immune signaling, or both. TLR3 and TLR4 also initiate the necroptosis mediated by TRIF and RIPK3 [40, 41]. Like RIPK3 and RIPK1, TRIF is also a cleavage substrate for caspase-8. TRIF-dependent necroptosis also requires interaction with RIPK3 through the RHIM domain while the role of RIPK1 is not clear. Several studies have reported that inhibition of RIPK1 in TLR3-mediated necroptosis does not impair this process [41]. Unlike RIPK, TRIF does not possess protein kinase activity which indicates that the mechanism by which 


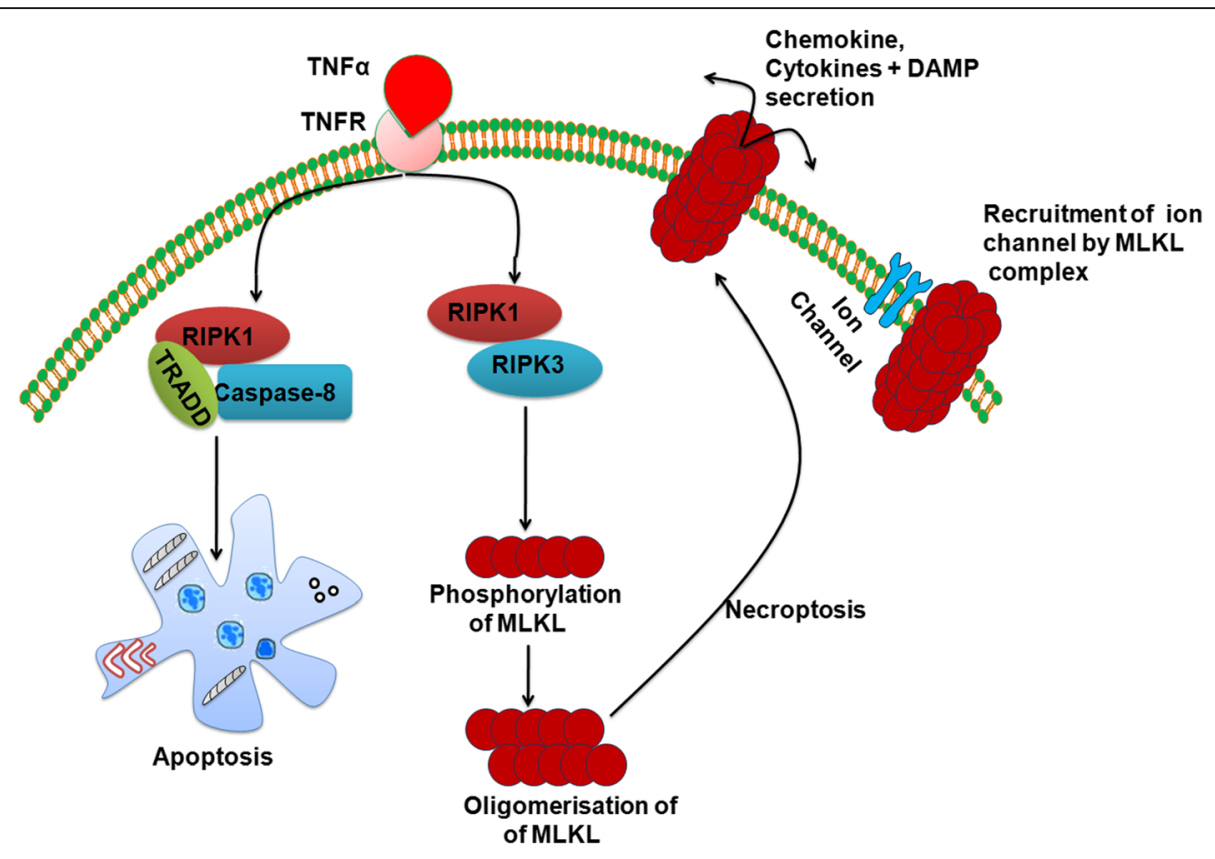

Fig. 1 Molecular mechanism of apoptosis and necroptosis. Death receptor mediates both extrinsic apoptosis as well as necroptosis; RIPK1 plays a key role in apoptosis and necroptosis. Activation of caspase-8 drives the pathway towards apoptosis while its inhibition leading to necroptosis. During necroptosis, RIPK1 and RIPK3 interact with each other resulting in the formation of functional heterodimer complex; this complex promotes oligomerization of MLKL by phosphorylating it. Oligomeric form of MLKL translocates towards the plasma membrane from cytosol resulting in the formation of the pore, causing an inflammatory response. In spite of pore formation, MLKL also mediates its effect after interacting with ion channels

TRIF activates the RIPK3 is different from RIPK1-mediated activation of RIPK3 and so this pathway is considered as non-classical necroptosis.

\section{Role of phospho-acceptor sites in RIPK1 and RIPK3}

Phosphorylation plays a major role in controlling the activity of proteins. Mass spectrometry analysis has shown that RIPK1 and RIPK3 have multiple sites for phosphorylation on $\mathrm{N}$-terminal kinase domain. Interestingly, expression of the truncated form of these proteins lacking $\mathrm{N}$-terminal kinase domain resulted in the formation of amyloid fibrils [3]. Phospho-acceptor sites in RIPK1 are ser89 and ser161. Addition of phosphate group on ser89 inhibits the activity of RIPK1; hence, this site is involved in regulation of RIPK1 activity during necroptosis. McQuade et al. [42] have reported that substitution of serine with glutamate (S89D-RIPK1) resulted in reduced activity of RIPK1 while in the case of S89A-RIPK1, kinase activity of RIPK1 is increased in contrast to wild-type RIPK1. Structural analysis of RIPK1 with B-Raf suggested that Ser161 is necessary for pro-necrotic activity of RIPK1. Pro-necrotic activity of RIPK1 has been found to reduce the substitution of serine with alanine (S161A-RIPK1) [3, 42]. In spite of this, Ser321 is also important for induction of RIPK1-mediated necroptosis, [43] and in addition, Newton et al. [44] have shown that autophosphorylation of Ser166 of RIPK1 also mediates the induction of necroptosis. The two major phosphorylation sites in RIPK3 are ser204 and ser232. Sequence homology experiments have shown that ser204 in mouse (ser199 in human) is conserved in different species. Experimental studies reported that substitution of ser at 204 (S204A-RIPK3) resulted in inhibition of necroptosis $[14,42]$. In spite of this, ser232 plays a key role in the recruitment of MLKL; phosphomimetic studies have shown that ser232 did not control kinase activity of RIPK3 while it disrupts the binding surface for MLKL $[10,42]$. Besides these, ser227 also mediates MLKL binding to RIPK3; phosphomimetic mutant at ser227 inhibits RIPK3-mediated necroptosis [10, 42]. These studies suggested that phosphorylation at ser227 allows permissive conformation in RIPK3 to interact with MLKL. Although, RIPK1 is an upstream kinase which activates RIPK3 but RIPK3 and can induce the necroptosis independently of RIPK1. Some studies have also shown that inducible dimerization of RIPK3 initiates the MLKL-dependent necroptosis [45-49] and these results suggested that RIPK1 promotes nucleation events for RIPK3 oligomerization.

\section{Necroptosis and its role in inflammation}

In case of apoptosis, secretion of cytokines is absent or very less, while during necroptosis, it is a primal event leading to robust inflammation. However, release of DAMP from cells is the primary way by which RIPK3 
stimulates the inflammatory response after insertion of MLKL. Recent studies have reported that RIPK3 also directly activates the formation of inflammasome which is formed in response to cellular stress or microbial infection to activate caspase- 1 and caspase- 11 . Further, caspase- 1 cleaves IL-1 $\beta$ into mature form [50] and this activation occurs via two distinct RIPK3-dependent pathways: one mediated by caspase- 8 and the other one mediated by NLPR3 (NOD, LRR, and pyrin) and leads to inflammasome formation [51]. A number of studies have shown that RIPK3 facilitates cytokine production and activation of inflammasome which is mediated by lipopolysaccharide (LPS) [52-56]. Several studies have reported that MLKL is essential for RIPK3-dependent inflammation (Fig. 2) while few studies reported that ablation of MLKL does not affect the RIPK3-dependent activation of NLPR3, IL-1 $\beta$ maturation, or cytokine production [57-59]. However, it is unknown how RIPK3 activates NLPR3-mediated formation of inflammasome with or without the involvement of MLKL. Some models explain that RIPK3 also acts as scaffold to recruit complex containing RIPK1, FADD, and caspase- $8[51,52,56,59,60]$. In this condition, caspase- 8 promotes the maturation of naive IL- $1 \beta$ by an unknown mechanism or activates the caspase-1 within NLPR3 inflammasome. However, some studies have shown that caspase- 8 also plays an inhibitory role by preventing RIPK3-MLKL-mediated assembly of NLPR3 [53].

In spite of RIPK3, RIPK1 also induces cytokine production independent of RIPK3. In some models, RIPK1 acts as scaffolds especially during TNF-mediated NF- $\mathrm{kB}$ and JNK activation leading to cytokine productions [61-63]. Recently, it was shown that RIPK1 is crucial in increasing the level of circulating IL- $1 \alpha$ for activation of NF-kB, FOS, and ERK following TLR4 activation [64], for secretion of TNF of TNF-treated cells in an autocrine fashion [65] and also for the induction of spontaneous inflammatory disease in SHIP (defective SH2 domain-containing inositol 5 '-phosphatase 1) defective mice [66]. The release of DAMPs either from dying cells or by RIPK1-RIPK3 inflammasome-dependent or RIPK1RIPK3 inflammasome-independent pathways varies depending on the cellular environment.

\section{Necroptosis: infectious and non-infectious diseases}

Necroptosis plays a key role in the production of cytokine driven by TNF on pathogen infection. TNF is a major driver of bacterial infection suggesting that necroptosis may also appear to be a pro-inflammatory factor in bacterial infection-induced inflammation. Escherichia coli-expressed NleB1 protein (pathogenicity effector protein) inhibits apoptosis and necroptosis by modifying arginine residue in proteins containing death domains such as FADD and RIPK1 [67, 68]. NleB1 (pathogenecity effector protein having $\mathrm{N}$-acetylglucosamine transferase activity)-deficient bacteria (E. coli) are unable to colonize in the intestine of the host which suggests that bacterium-induced cell death protects the host organism. In addition to this, RIPK3 deficiency in combination with caspase-8 or FADD leads to increased susceptibility to Yersinia infection $[13,69]$. Several studies have shown that many bacteria stimulate RIPK3-mediated necroptosis [70-73]. Consistent with this, RIPK3-dependent necroptosis and TNF expression have been observed in tissues infected with Mycobacterium tuberculosis [72], further suggesting that necroptosis plays a key role in bacterial-induced chronic inflammation. Roca and

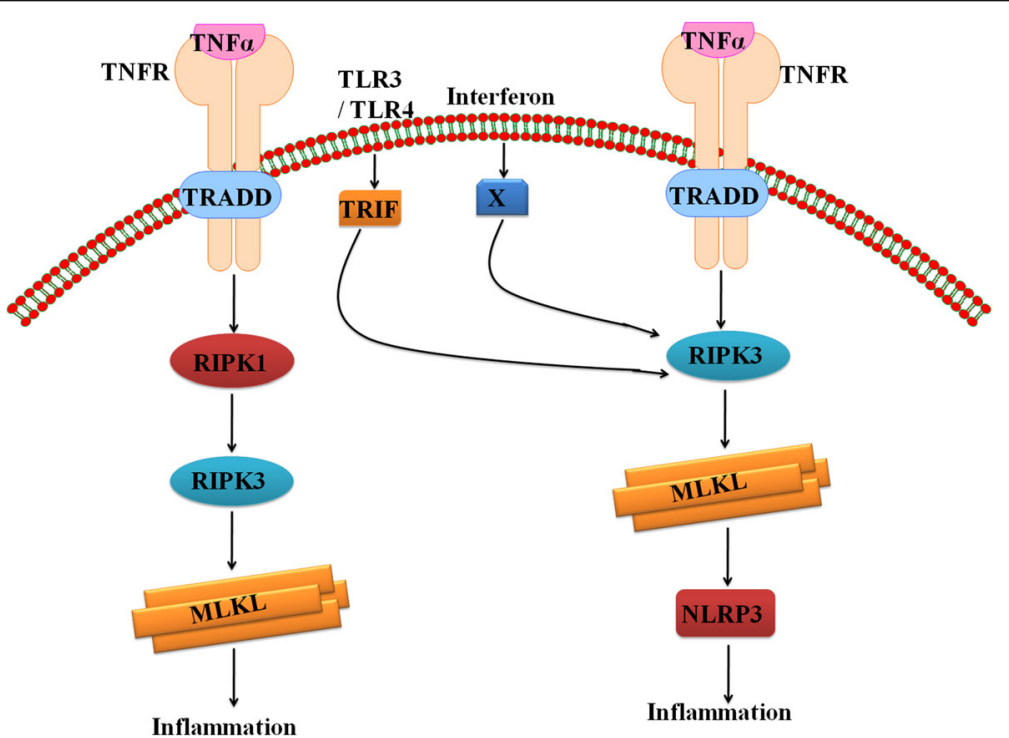

Fig. 2 RIPK-dependent inflammation. RIPK3 kinase activity, critical for oligomerization of MLKL that culminates with inflammation. Activation of RIPK3 is mediated by RIPK1 as well as other mediators like TLR3/TLR4 and interferon 
Ramakrishnan [72] also showed that RIPK1/RIPK3 are both essential to stimulate TNF-dependent generation of reactive oxygen species (ROS) in tuberculosis infection. Experimental studies have also shown that upregulation of RIPK3 and MLKL detected in alcoholic and drug-induced liver injury suggests that necroptosis is also involved in sterile inflammation. Application of Necrostatin (Nec)-1 or depletion of RIPK3 protects liver cells from these types of injuries [74]. Parasitic diseases like leishmaniasis and malaria generally caused hemolysis, anemia, and sometimes bleeding. These result due to rupturing of red blood corpuscles (RBCs) leading to release of hemoglobin $(\mathrm{Hb})$ into circulation; heme is produced on oxidation of $\mathrm{Hb}$ leading to initiation of the Fenton reaction and culminates with generation of ROS. Heme is also responsible for direct activation of TLR4, leading to autocrine secretion of ROS and TNF, and they activate the RIPK1/3-dependent necroptosis in a synergistic manner [75].

In spite of this, RIPK/MLKL-mediated necroptosis also plays a key role in destructive inflammation during viral infection. Viruses use the signaling pathways of the host to potentiate infection such as anti-apoptotic proteins encoded by viruses which increase its ability to replicate inside the host cell. Upton et al. [76] have shown that viral (mouse cytomegalovirus and M45-encoded viral inhibitor of RIPK activation) encoding protein containing the RHIM domain interacts with RIPK1 and RIPK3 and inhibits virus-induced cell death. Viral inhibitor of RIPK activation (vRIA) disrupts the binding of RIPK3 with DNA-dependent activator of IRFs (DAI) which results in suppression of cytomegalovirus-mediated necroptosis [77] while human cytomegalovirus-encoded different protein (IE1-immediate early gene 1) which does not disrupt the binding of RIPK3 with DAI; it acts by inhibiting signaling downstream of MLKL [78]. Experimental studies carried out on mice lacking RIPK3 exhibit impaired virus-induced necroptosis and increased sensitivity to viral infection $[8,13,77,79,80]$. Regulation of necroptosis by viruses appears to be detrimental to the host under some circumstances such as in the case of HIV infection which induces necroptosis in immune cells required for infection control. The rate of necroptosis was increased in HIV-infected T cells which were correlated with decreased caspase-8 activity [81] and higher sensitivity to TNF-mediated cell death [82]. Several studies have reported the role of necroptosis in multiple tissues in ischemia-reperfusion condition [83-85]. In addition to this, fewer necrotic areas and less pro-inflammatory cytokine expression in active necroptosis lesson has been found in RIPK3-deficient mice; they are also more resistant to the development of atherosclerosis $[86,87]$.

\section{Necroptosis and neurodegenerative disease}

Necroptosis was characterized initially in ischemic brain. Several lines of evidences have reported that necroptosis not only caused pathogenesis of neurodegenerative diseases such as Parkinson's disease [88], amyotrophic lateral sclerosis [89, 90], and multiple sclerosis (MS) [91] but is also involved in other neurodegenerative conditions including spinal cord injury $[92,93]$ and retinal degeneration $[63,94,95]$. A secondary pathological feature in the patient of spinal cord injury is chronic inflammation, astrogliosis, and cavity formation [96]. Some studies have shown that application of $\mathrm{Nec}-1$ has a protective effect in spinal cord injury (SCI) [14, 97]. A recent study has reported that expression of RIPK3 and phosphorylated MLKL increased in reactive astrocytes and microglia after SCI [92, 98]. M1 microglia induced TLR/myeloid differentiation signaling-dependent necroptosis leading to cell death of reactive astrocytes which line the spinal cavity [92], and microglia plays a key role during chronic inflammation post-SCI [98]. Microglial-mediated chronic inflammation further raises questions how programmed necrosis regulates the chronic inflammation after SCI. Multiple sclerosis is an autoimmune disease of the brain characterized by demyelination and chronic inflammation. Ofengeim et al. [91] have reported that TNF $\alpha$ induces the death of oligodendrocytes in a RIPK1/3-dependent manner. Increased level of TNF- $\alpha$, IL-1 $\beta$, and RIPK3 in microglia and neurons in the mouse model mimics the characteristic of Gaucher's disease, a metabolic disorder of the brain. Amyotrophic lateral sclerosis (ALS), a well-known motor neuron degenerative disease, is characterized by inflammation which is a hallmark of ALS. Re et al. [99] have shown that motor neuron undergoes necroptosis by using the spinal cord of the ALS model. Further, these reports suggested that neuronal cell type-specific necroptosis occurs in neurodegenerative diseases. Recent studies have been noted that application of Nec-1 has a protective effect on dopaminergic neurons after treatment of 6-OHDA to PC12 cells and diminished the expression of LC3, involved in autophagy. These results indicated that expression of RIPK1 is high in the Parkinson disease (PD) model [88].

\section{Necroptosis-therapeutic approach for neurodegenerative disease}

The protective and inflammatory effects of necroptosis in pathological condition of neurodegenerative diseases are used to develop effective treatments. In recent times, there are some inhibitors (or compounds) which are used to treat the neurodegenerative diseases such as NEC-1, HDAC inhibitors, and 24(S)-hydroxycholesterol. Nec-1 diminished the activity of RIPK1 by inhibiting its phosphorylation and translocation resulting in disruption of downstream necroptosis signaling [3]. In spite of necroptosis, Nec-1 also inhibits apoptosis and autophagy through activating Akt and mTOR 
signal pathways after traumatic brain injury (TBI) [100]. Previous studies based on Nec-1 demonstrated that inhibition of RIPK1 blocked the cell death including necroptosis and apoptosis in an animal model of degenerative diseases. Using Nec-1 with zVAD-fmk produced promising treatment effects in neurodegenerative diseases [2], suggesting that there is great complementarily between necroptosis and apoptosis. 24(S)-Hydroxycholesterol (24S-OHC) plays a key role in maintaining cholesterol homeostasis in the brain and considered as a possible biomarker of neurodegenerative diseases [101]. Ester form of 24S-OHC inhibits amyloid- $\beta$ production at physiological concentration while at high concentration it induces non-apoptotic programmed cell death in neuronal cells with low expression of caspase-8; hence, controlling the level of 24S-OHC may prevent onset of progressive neurodegenerative diseases [101]. Histone modifications have a great impact on epigenetic modulation of transcription in cells. Acetylation and deacetylation are two important modifications involved in regulation of transcription status of cells. Deacetylation of histone protein results in chromatin condensation and transcriptional inhibition in neurodegenerative diseases including Huntington's disease and PD [102-104], suggesting that HDAC is closely related with necroptosis in contrast to apoptosis. Suberoylanilide hydroxamic acid (SAHA) is a most appropriate necroptotic inhibitor which could protect cells from necroptosis [97] by enhancing the expression of cFLIPL, NF- $k B$, and P38 while inactivating the JNK [49].

ALS is a rare progressive neurodegenerative disease which affects the nerve of the brain and spinal cord leading to weakening/hardening of muscles on onset of age, and there is no effective treatment to reverse the natural course of ALS by far. Ablation in function of optineurin (OPTN) [64] and superoxide dismutase-1 (SOD1) [99] resulted in pathogenesis of ALS. Mutation in OPTN gene actively initiates the RIPK1-dependent signaling resulting in progressive axonal degeneration and demyelination in ALS patients. Interestingly, axonal degeneration and motor dysfunction have been found to reduce in SOD1 G93A transgenic mice on silencing of RIPK3 or Nec-1 (7-Cl-O-Nec-1) stimulation [89] and suggested that astrocytes in motor neuron of ALS patient stimulate necroptosis in RIPK1/MLKL-dependent manner. Degeneration of motor neuron in ALS patient was found to be dead due to necroptosis in in vitro model of human adult primary sporadic ALS [99]. Treatment of ALS patient with necrosulfonamide (NSA) or RIPK1 knockdown resulted in survival of neighboring motor neuron [89, 99]. In necroptotic astrocytes, expression of TLR and myeloid differentiation primary response gene 88 (MyD88) has been found to be upregulated during inflammatory responses. Recently, it was found that activated astrocytes undergo transformation into M1 microglia/macrophages mediated by TLR/MyD88 signaling cascade [92]. Pirooznia et al. [105] have shown that human adult astrocytes of familial and sporadic ALS secreted pro-inflammatory cytokines resulting in the death of neighboring motor neurons through necroptosis. Further, these studies indicated that necroptosis might be a novel target for the treatment of ALS. In spite of this, Nec-1 also ameliorates another neurodegenerative disease (Table 1).

\section{Conclusion}

Necroptosis, a new type of cell death pathway, and its molecular players contribute to embryonic and postnatal development. In spite of all this, they also participate in tissue homeostasis and in development of various kinds of pathological conditions. Necroptosis is an emerging field closely related to apoptosis and targeting RIPK 3 and RIPK1 may help to overcome therapeutic hurdles in the treatment of inflammatory and neurodegenerative diseases. The process of inflammation is a highly complicated process which results due to coordination of different players of the immune system. Necroptosis affects different cell population of the immune system in a temporal and spatial manner. Hence, it is necessary to unveil the molecular mechanism through which necroptosis process regulates the phenotype of immune cells. Further, unrevealing the immunostimulatory mechanisms from apoptosis to necroptosis will be helpful to understand necroptosis. In spite of necroptosis, RIPK3/RIPK1 also mediates no-necroptosis pathway; hence, carefully dissecting these pathways will provide better targets for therapeutic approaches in the nearby future.

Table 1 Role of Nec-1 in neurodegenerative diseases

\begin{tabular}{llll}
\hline S. no. & Neurodegenerative disease & Role of Nec-1 & References \\
\hline 1 & Alzheimer's disease & Nec-1 promotes the neural cell death and improves neurobehavior in Al-treated mice model. \\
& Nec-1 also ameliorates cognitive dysfunction, significantly reducing the level of AB and tau in & [107] \\
& APP/PS1 mice model. & [108] \\
3 & Parkinson's disease & Nec-1 enhanced the cell survival in 6-OHDA-treated PC12 cells & [100] \\
\hline
\end{tabular}




\section{Acknowledgements}

The authors acknowledge Dr. Nirmala Deo (NJIL and OMD), India, and Dr. Sandeep Sharma, USA, for proofreading the manuscript.

\section{Authors' contributions}

YKD and DS designed the concept, wrote the manuscript, and finalized it. Both authors read and approved the final manuscript.

\section{Ethics approval and consent to participate}

Not applicable

\section{Consent for publication}

Not applicable

\section{Competing interests}

The authors declare that they have no competing interests.

\section{Publisher's Note}

Springer Nature remains neutral with regard to jurisdictional claims in published maps and institutional affiliations.

\section{Author details}

'Developmental Toxicology Laboratory, Systems Toxicology and Health Risk Assessment Group, CSIR-Indian Institute of Toxicology Research (CSIR-IITR), Vishvigyan Bhawan; 31, Mahatma Gandhi Marg, Lucknow 226001, India. ${ }^{2}$ Academy of Scientific and Innovative Research (AcSIR) Lucknow Campus, Lucknow, India. ${ }^{3}$ Department of Biochemistry, National JALMA Institute for Leprosy and Other Mycobacterial Diseases, Tajganj, Agra, India. ${ }^{4}$ Interdisciplinary Biotechnology Unit, Aligarh Muslim University, Aligarh 202002, India.

Received: 24 February 2018 Accepted: 22 June 2018 Published online: 06 July 2018

\section{References}

1. Galluzzi L, Vitale I, Abrams JM, Alnemri ES, Baehrecke EH, Blagosklonny MV et al. Molecular definitions of cell death subroutines: recommendations of the Nomenclature Committee on Cell Death. Cell Death Differ. 2012;19:107.

2. Degterev A, Huang Z, Boyce M, Li Y, Jagtap P, Mizushima N, et al. Chemical inhibitor of nonapoptotic cell death with therapeutic potential for ischemic brain injury. Nat Chem Biol. 2005;1:112-9.

3. Degterev A, Hitomi J, Germscheid M, Ch'en IL, Korkina O, Teng X, et al. Identification of RIP1 kinase as a specific cellular target of necrostatins. Nat Chem Biol. 2008;4:313-21.

4. Berghe TV, Linkermann A, Jouan-Lanhouet S, Walczak H, Vandenabeele P. Regulated necrosis: the expanding network of non-apoptotic cell death pathways. Nat Rev Mol Cell Biol. 2014;15:135-47.

5. Taylor RC, Cullen SP, Martin SJ. Apoptosis: controlled demolition at the cellular level. Nat Rev Mol Cell Biol. 2008:9:231-41.

6. Vercammen D, Beyaert R, Denecker G, Goossens V, Van Loo G, Declercq W et al. Inhibition of caspases increases the sensitivity of $L 929$ cells to necrosis mediated by tumor necrosis factor. J Exp Med. 1998;187:1477-85.

7. Holler N, Zaru R, Micheau O, Thome M, Attinger A, Valitutti S, et al. Fas triggers an alternative, caspase-8- independent cell death pathway using the kinase RIP as effector molecule. Nat Immunol. 2000;1:489-95.

8. Cho Y, Challa S, Moquin D, Genga R, Ray TD, Guildford M, Chan FK. Phosphorylation-driven assembly of the RIP1-RIP3 complex regulates programmed necrosis and virus-induced inflammation. Cell. 2009:137:1112-23.

9. Zhang DW, Shao J, Lin J, Zhang N, Lu BJ, Lin SC, et al. RIP3, an energy metabolism regulator that switches TNF-induced cell death from apoptosis to necrosis. Science. 2009;325:332-6.

10. Sun $X$, Lee J, Navas T, Baldwin DT, Stewart TA, Dixit VM. RIP3, a novel apoptosis-inducing kinase. J Biol Chem. 1999;274:16871-5.

11. Dondelinger $Y$, Declercq W, Montessuit S, Roelandt R, Goncalves A, Bruggeman I, et al. MLKL compromises plasma membrane integrity by binding to phosphatidylinositol phosphates. Cell Rep. 2014;7:971-81.

12. Hildebrand JM, Tanzer MC, Lucet IS, Young SN, Spall SK, Sharma P, et al. Activation of the pseudokinase MLKL unleashes the four-helix bundle domain to induce membrane localization and necroptotic cell death. Proc Natl Acad Sci. 2014;111:15072-7.
13. Wang H, Sun L, Su L, Rizo J, Liu L, Wang LF, et al. Mixed lineage kinase domain-like protein MLKL causes necrotic membrane disruption upon phosphorylation by RIP3. Mol Cell. 2014;54:133-46.

14. He S, Wang L, Miao L, Wang T, Du F, Zhao L, Wang X. Receptor interacting protein kinase-3 determines cellular necrotic response to TNF-a. Cell. 2009; 137:1100-11.

15. Murphy JM, Czabotar PE, Hildebrand JM, Lucet IS, Zhang JG, Alvarez-Diaz S, et al. The pseudokinase MLKL mediates necroptosis via a molecular switch mechanism. Immunity. 2013;39:443-53.

16. O'Donnell MA, Perez-Jimenez E, Oberst A, Ng A, Massoumi R, Xavier R, et al. Caspase 8 inhibits programmed necrosis by processing CYLD. Nat Cell Biol. 2011;13:1437-42.

17. Van Raam BJ, Ehrnhoefer DE, Hayden MR, Salvesen GS. Intrinsic cleavage of receptor-interacting protein kinase-1 by caspase-6. Cell Death Differ. 2013; 20:86-96.

18. Ofengeim D, Yuan J. Regulation of RIP1 kinase signalling at the crossroads of inflammation and cell death. Nat Rev Mol Cell Biol. 2013;14:727-36.

19. Sedger LM, McDermott MF. TNF and TNF-receptors: from mediators of cell death and inflammation to therapeutic giants-past, present and future. Cytokine Growth Factor Rev. 2014;25:453-72.

20. Kalliolias GD, Ivashkiv LB. TNF biology, pathogenic mechanisms and emerging therapeutic strategies. Nat Rev Rheumatol. 2016;12:49-62.

21. Cullen SP, Henry CM, Kearney CJ, Logue SE, Feoktistova M, Tynan GA, et al. Fas/CD95-induced chemokines can serve as "find-me" signals for apoptotic cells. Mol Cell. 2013;49:1034-48.

22. Moriwaki K, Chan FKM. Regulation of RIPK3-and RHIM-dependent necroptosis by the proteasome. J Biol Chem. 2016;291:5948-59.

23. Kaczmarek A, Vandenabeele P, Krysko DV. Necroptosis: the release of damage-associated molecular patterns and its physiological relevance. Immunity. 2013:38:209-23.

24. Duprez L, Takahashi N, Van Hauwermeiren F, Vandendriessche B, Goossens V, Vanden Berghe T, et al. RIP kinase-dependent necrosis drives lethal systemic inflammatory response syndrome. Immunity. 2011; 35:908-18.

25. Micheau O, Tschopp J. Induction of TNF receptor I-mediated apoptosis via two sequential signaling complexes. Cell. 2003:114:181-90.

26. Han J, Zhong CQ, Zhang DW. Programmed necrosis: backup to and competitor with apoptosis in the immune system. Nat Immunol. 2011:12:1143-9.

27. Vandenabeele P, Galluzzi L, Berghe TV, Kroemer G. Molecular mechanisms of necroptosis: an ordered cellular explosion. Nat Rev Mol Cell Biol. 2010;11:700-14.

28. Newton K, Dugger DL, Wickliffe KE, Kapoor N, de Almagro MC, Vucic D, et al. Activity of protein kinase RIPK3 determines whether cells die by necroptosis or apoptosis. Science. 2014;343:1357-60.

29. Kreuz $S$, Siegmund D, Scheurich $P$, Wajant $H$. NF-kB inducers upregulate CFLIP, a cycloheximide-sensitive inhibitor of death receptor signaling. Mol Cell Biol. 2001:21:3964-73.

30. Papa S, Zazzeroni F, Bubici C, Jayawardena S, Alvarez K, Matsuda S, et al Gadd45 [beta] mediates the NF-[kappa] B suppression of JNK signalling by targeting MKK7/JNKK2. Nat Cell Biol. 2004;6:146-53.

31. Oberst A, Dillon CP, Weinlich R, McCormick LL, Fitzgerald P, Pop C, et al. Catalytic activity of the caspase-8-FLIPL complex inhibits RIPK3-dependent necrosis. Nature. 2011:471:363.

32. Pop C, Oberst A, Drag M, Van Raam BJ, Riedl SJ, Green DR, Salvesen GS. FLIPL induces caspase 8 activity in the absence of interdomain caspase 8 cleavage and alters substrate specificity. Biochem J. 2011;433:447-57.

33. Xie T, Peng W, Yan C, Wu J, Gong X, Shi Y. Structural insights into RIP3mediated necroptotic signaling. Cell Rep. 2013;5:70-8.

34. Dondelinger $Y$, Aguileta MA, Goossens V, Dubuisson C, Grootjans S, Dejardin E, et al. RIPK3 contributes to TNFR1-mediated RIPK1 kinase-dependent apoptosis in conditions of CIAP1/2 depletion or TAK1 kinase inhibition. Cell Death Differ. 2013;20:1381-92

35. Cai Z, Jitkaew S, Zhao J, Chiang HC, Choksi S, Liu J, et al. Plasma membrane translocation of trimerized MLKL protein is required for TNF-induced necroptosis. Nat Cell Biol. 2014;16:55-65.

36. Wang $Z$, Jiang $H$, Chen $S$, Du F, Wang $X$. The mitochondrial phosphatase PGAM5 functions at the convergence point of multiple necrotic death pathways. Cell. 2012;148:228-43.

37. Tait SW, Oberst A, Quarato G, Milasta S, Haller M, Wang R, et al. Widespread mitochondrial depletion via mitophagy does not compromise necroptosis. Cell Rep. 2013;5:878-85. 
38. Li J, McQuade T, Siemer AB, Napetschnig J, Moriwaki K, Hsiao YS, et al. The RIP1/RIP3 necrosome forms a functional amyloid signaling complex required for programmed necrosis. Cell. 2012;150:339-50.

39. Zhang Y, Su SS, Zhao S, Yang Z, Zhong CQ, Chen X et al. RIP1 autophosphorylation is promoted by mitochondrial ROS and is essential for RIP3recruitment into necrosome. Nat Commun. 2017:8:14329.

40. He S, Liang Y, Shao F, Wang X. Toll-like receptors activates programmed necrosis in macrophages through a receptor-interacting kinase-3-mediated pathway. Proc Natl Acad Sci. 2011;108:20054-9.

41. Kaiser WJ. Toll-like receptor 3-mediated necrosis via TRIF, RIP3, and MLKL. J Biol Chem. 2013;288:31268-79.

42. McQuade T, Cho Y, Chan FKM. Positive and negative phosphorylation regulates RIP1-and RIP3-induced programmed necrosis. Biochem J. 2013; 456:409-15.

43. Jaco I, Annibaldi A, Lalaoui N, Wilson R, Tenev T, Laurien L, Chau D. MK2 phosphorylates RIPK1 to prevent TNF-induced cell death. Mol Cell. 2017;66: 698-710.

44. Newton K, Wickliffe KE, Maltzman A, Dugger DL, Strasser A, Pham VC, et al. RIPK1 inhibits ZBP1-driven necroptosis during development. Nature. 2016; 540:129-33.

45. Wu XN, Yang $Z H$, Wang $X K$, Zhang $Y$, Wan $H$, Song $Y$, et al. Distinct roles of RIP1-RIP3 hetero- and RIP3-RIP3 homo-interaction in mediating necroptosis. Cell Death Differ. 2014;21:1709-20.

46. Orozco S, Yatim N, Werner MR, Tran H, Gunja SY, Tait SW, et al. RIPK1 both positively and negatively regulates RIPK3 oligomerization and necroptosis. Cell Death Differ. 2014;21:1511-21.

47. Sun L, Wang H, Wang Z, He S, Chen S, Liao D, Wang X. Mixed lineage kinase domain-like protein mediates necrosis signaling downstream of RIP3 kinase. Cell. 2012;148:213-27.

48. Cook WD, Moujalled DM, Ralph TJ, Lock P, Young SN, Murphy JM, Vaux DL. RIPK1- and RIPK3-induced cell death mode is determined by target availability. Cell Death Differ. 2014;21:1600.

49. Zhao J, Jitkaew S, Cai Z, Choksi S, Li Q, Luo J, Liu ZG. Mixed lineage kinase domain-like is a key receptor interacting protein 3 downstream component of TNF-induced necrosis. Proc Natl Acad Sci. 2012;109:5322-7.

50. Man SM, Tourlomousis P, Hopkins L, Monie TP, Fitzgerald KA, Bryant CE. Salmonella infection induces recruitment of Caspase- 8 to the inflammasome to modulate IL-1 $\beta$ production. J Immunol. 2013;191:5239-46.

51. Vince JE, Wong WW, Gentle I, Lawlor KE, Allam R, O'Reilly L, et al. Inhibitor of apoptosis proteins limit RIP3 kinase-dependent interleukin-1 activation. Immunity. 2012;36:215-27.

52. Antonopoulos C, El Sanadi C, Kaiser WJ, Mocarski ES, Dubyak GR. Proapoptotic chemotherapeutic drugs induce noncanonical processing and release of IL-1 $\beta$ via caspase-8 in dendritic cells. J Immunol. 2013; 191:4789-803.

53. Kang TB, Yang SH, Toth B, Kovalenko A, Wallach D. Caspase-8 blocks kinase RIPK3-mediated activation of the NLRP3 inflammasome. Immunity. 2013;38: 27-40.

54. Yabal M, Müller N, Adler H, Knies N, Grob CJ, Damgaard RB, et al. XIAP restricts TNF-and RIP3-dependent cell death and inflammasome activation. Cell Rep. 2014:7:1796-808.

55. Kang S, Fernandes-Alnemri T, Rogers C, Mayes L, Wang Y, Dillon C, et al. Caspase-8 scaffolding function and MLKL regulate NLRP3 inflammasome activation downstream of TLR3. Nat Commun. 2015;6:7515.

56. Moriwaki K, Bertin J, Gough PJ, Chan FKM. A RIPK3-caspase 8 complex mediates atypical pro-IL-1 $\beta$ processing. J Immunol. 2015;194:1938-44.

57. Weng D, Marty-Roix R, Ganesan S, Proulx MK, Vladimer Gl, Kaiser WJ, et al. Caspase- 8 and RIP kinases regulate bacteria-induced innate immune responses and cell death. Proc Natl Acad Sci. 2014;111:7391-6.

58. Wong WW, Vince JE, Lalaoui N, Lawlor KE, Chau D, Bankovacki A, et al. clAPs and XIAP regulate myelopoiesis through cytokine production in an RIPK1and RIPK3-dependent manner. Blood. 2014;123:2562-72.

59. Lawlor KE, Khan N, Mildenhall A, Gerlic M, Croker BA, D'Cruz AA, et al. RIPK3 promotes cell death and NLRP3 inflammasome activation in the absence of MLKL. Nat Commun. 2015;6:6282.

60. Conos SA, Chen KW, De Nardo D, Hara H, Whitehead L, Núñez G, Lawlor KE. Active MLKL triggers the NLRP3 inflammasome in a cell-intrinsic manner. Proc Natl Acad Sci USA. 2017;114:E961-9.

61. Hsu H, Huang J, Shu HB, Baichwal V, Goeddel DV. TNF-dependent recruitment of the protein kinase RIP to the TNF receptor-1 signaling complex. Immunity. 1996;4:387-96.
62. Liu ZG, Hsu H, Goeddel DV, Karin M. Dissection of TNF receptor 1 effector functions: JNK activation is not linked to apoptosis while NF-KB activation prevents cell death. Cell. 1996;87:565-76.

63. Barabino A, Plamondon V, Abdouh M, Chatoo W, Flamier A, Hanna R, et al. Loss of Bmi1 causes anomalies in retinal development and degeneration of cone photoreceptors. Development. 2016;143:1571-84.

64. Bury JJ, Highley JR, Cooper-Knock J, Goodall EF, Higginbottom A, McDermott CJ, et al. Oligogenic inheritance of optineurin (OPTN) and C9ORF72 mutations in ALS highlights localisation of OPTN in the TDP-43negative inclusions of C9ORF72-ALS. Neuropathology. 2016;36:125-34.

65. Christofferson DE, Li Y, Hitomi J, Zhou W, Upperman C, Zhu H, et al. A novel role for RIP1 kinase in mediating TNFa production. Cell Death Dis. 2012;3:e320.

66. Lukens JR, Vogel $P$, Johnson GR, Kelliher MA, Iwakura Y, Lamkanfi M, Kanneganti TD. RIP1-driven autoinflammation targets IL-1a independently of inflammasomes and RIP3. Nature. 2013;498:224-7.

67. Li S, Zhang L, Yao Q, Li L, Dong N, Rong J, et al. Pathogen blocks host death receptor signalling by arginine GICNAcylation of death domains. Nature. 2013;501:242-6.

68. Pearson JS, Giogha C, Ong SY, Kennedy CL, Kelly M, Robinson KS, et al. A type III effector antagonises death receptor signalling during bacterial gut infection. Nature. 2013;501:247-51.

69. Philip NH, Dillon CP, Snyder AG, Fitzgerald P, Wynosky-Dolfi MA, Zwack EE, et al. Caspase- 8 mediates caspase- 1 processing and innate immune defense in response to bacterial blockade of NF-KB and MAPK signaling. Proc Natl Acad Sci. 2014;111:7385-90.

70. Robinson N, McComb S, Mulligan R, Dudani R, Krishnan L, Sad S. Type I interferon induces necroptosis in macrophages during infection with Salmonella enterica serovar Typhimurium. Nat Immunol. 2012;13:954-62.

71. Autheman D, Wyder M, Popoff M, D'Herde K, Christen S, Posthaus H. Clostridium perfringens beta-toxin induces necrostatin-inhibitable, calpain-dependent necrosis in primary porcine endothelial cells. PLoS One. 2013:8:e64644.

72. Roca FJ, Ramakrishnan L. TNF dually mediates resistance and susceptibility to mycobacteria via mitochondrial reactive oxygen species. Cell. 2013;153: 521-34

73. Kitur K, Parker D, Nieto P, Ahn DS, Cohen TS, Chung S, et al. Toxin-induced necroptosis is a major mechanism of Staphylococcus aureus lung damage. PLoS Pathog. 2015:11:e1004820.

74. Roychowdhury S, McMullen MR, Pisano SG, Liu X, Nagy LE. Absence of receptor interacting protein kinase 3 prevents ethanol-induced liver injury. Hepatology. 2013;57:1773-83.

75. Fortes GB, Alves LS, de Oliveira R, Dutra FF, Rodrigues D, Fernandez PL, et al. Heme induces programmed necrosis on macrophages through autocrine TNF and ROS production. Blood. 2012;119:2368-75.

76. Upton JW, Kaiser WJ, Mocarski ES. Cytomegalovirus M45 cell death suppression requires receptor-interacting protein (RIP) homotypic interaction motif (RHIM)-dependent interaction with RIP1. J Biol Chem. 2008;283:16966-70.

77. Upton JW, Kaiser WJ, Mocarski ES. DAI/ZBP1/DLM-1 complexes with RIP3 to mediate virus-induced programmed necrosis that is targeted by murine cytomegalovirus vIRA. Cell Host Microbe. 2012;11:290-7.

78. Omoto S, Guo H, Talekar GR, Roback L, Kaiser WJ, Mocarski ES. Suppression of RIP3-dependent necroptosis by human cytomegalovirus. J Biol Chem. 2015;290:11635-48.

79. Huang Z, Wu SQ, Liang Y, Zhou X, Chen W, Li L, et al. RIP1/RIP3 binding to HSV-1 ICP6 initiates necroptosis to restrict virus propagation in mice. Cell Host Microbe. 2015;17:229-42.

80. Nogusa S, Thapa RJ, Dillon CP, Liedmann S, Oguin TH 3rd, Ingram JP, et al RIPK3 activates parallel pathways of MLKL-driven necroptosis and FADDmediated apoptosis to protect against influenza A virus. Cell Host Microbe. 2016:20:13-24.

81. Gaiha GD, McKim KJ, Woods M, Pertel T, Rohrbach J, Barteneva N, et al. Dysfunctional HIV-specific CD8+ T cell proliferation is associated with increased caspase-8 activity and mediated by necroptosis. Immunity. 2014; 41:1001-12

82. Pan $T$, Wu S, He X, Luo H, Zhang Y, Fan M, et al. Necroptosis takes place in human immunodeficiency virus type-1 (HIV-1)-infected CD4+ T lymphocytes. PLoS One. 2014:9:e93944.

83. Linkermann A, Bräsen JH, Darding M, Jin MK, Sanz AB, Heller JO, et al. Two independent pathways of regulated necrosis mediate ischemia-reperfusion injury. Proc Natl Acad Sci. 2013;110:12024-9. 
84. Koshinuma S, Miyamae M, Kaneda K, Kotani J, Figueredo VM. Combination of necroptosis and apoptosis inhibition enhances cardioprotection against myocardial ischemia-reperfusion injury. J Anesth. 2014;28:235-41.

85. Gao S, Andreeva K, Cooper NG. Ischemia-reperfusion injury of the retina is linked to necroptosis via the ERK1/2-RIP3 pathway. Mol Vis. 2014;20:1374-87.

86. Lin J, Li H, Yang M, Ren J, Huang Z, Han F, et al. A role of RIP3-mediated macrophage necrosis in atherosclerosis development. Cell Rep. 2013;3:200-10.

87. Meng L, Jin W, Wang X. RIP3-mediated necrotic cell death accelerates systematic inflammation and mortality. Proc Natl Acad Sci. 2015;112:11007-12.

88. Wu JR, Wang J, Zhou SK, Yang L, Yin JL, Cao JP, Cheng YB. Necrostatin-1 protection of dopaminergic neurons. Neural Regen Res. 2015;10:1120-4.

89. Ito Y, Ofengeim D, Najafov A, Das S, Saberi S, Li Y, et al. RIPK1 mediates axonal degeneration by promoting inflammation and necroptosis in ALS. Science. 2016;353:603-8.

90. Politi K, Przedborski S. Axonal degeneration: RIPK1 multitasking in ALS. Curr Biol. 2016;26:R932-4.

91. Ofengeim D, Ito $Y$, Najafov A, Zhang Y, Shan B, DeWitt JP, et al. Activation of necroptosis in multiple sclerosis. Cell Rep. 2015;10:1836-49.

92. Fan H, Zhang K, Shan L, Kuang F, Chen K, Zhu K, et al. Reactive astrocytes undergo M1 microglia/macrohpages-induced necroptosis in spinal cord injury. Mol Neurodegener. 2016;11:14.

93. Wu C, Chen J, Liu Y, Zhang J, Ding W, Wang S, et al. Upregulation of PSMB4 is associated with the necroptosis after spinal cord injury. Neurochem Res. 2016:41:3103-12.

94. Viringipurampeer IA, Metcalfe AL, Bashar AE, Sivak O, Yanai A, Mohammadi Z, et al. NLRP3 inflammasome activation drives bystander cone photoreceptor cell death in a $\mathrm{P} 23 \mathrm{H}$ rhodopsin model of retinal degeneration. Hum Mol Genet. 2016;25:1501-16.

95. Kim HI, Paik SS, Kim GH, Kim M, Kim SH, Kim IB. Neuroprotective effect of NecroX-5 against retinal degeneration in rodents. Neuroreport. 2016;27:1128-33.

96. Ju G, Wang J, Wang Y, Zhao X. Spinal cord contusion. Neural Regen Res. 2014;9:789-94.

97. Wang D, Zhao M, Chen G, Cheng X, Han X, Lin S, et al. The histone deacetylase inhibitor vorinostat prevents TNFa-induced necroptosis by regulating multiple signaling pathways. Apoptosis. 2013;18:1348-62

98. Fan $H$, Tang HB, Kang J, Shan L, Song H, Zhu K, et al. Involvement of endoplasmic reticulum stress in the necroptosis of microglia/macrophages after spinal cord injury. Neuroscience. 2015;311:362-73.

99. Re DB, Le Verche V, Yu C, Amoroso MW, Politi KA, Phani S, et al. Necroptosis drives motor neuron death in models of both sporadic and familial ALS. Neuron. 2014;81:1001-8.

100. Zhu S, Zhang Y, Bai G, Li H. Necrostatin-1 ameliorates symptoms in R6/2 transgenic mouse model of Huntington's disease. Cell Death Dis. 2011;2:e115.

101. Noguchi N, Saito Y, Urano Y. Diverse functions of 24 (S)-hydroxycholestero in the brain. Biochem Biophys Res Commun. 2014;446:692-6.

102. Sharma S, Taliyan R. Transcriptional dysregulation in Huntington's disease: the role of histone deacetylases. Pharmacol Res. 2015a;100:157-69.

103. Sharma S, Taliyan R. Targeting histone deacetylases: a novel approach in Parkinson's disease. Parkinsons Dis. 2015b;2015:303294.

104. Layman WS, Williams DM, Dearman JA, Sauceda MA, Zuo J. Histone deacetylase inhibition protects hearing against acute ototoxicity by activating the Nf-kB pathway. Cell Death Discov. 2015;1.

105. Pirooznia SK, Dawson VL, Dawson TM. Motor neuron death in ALS: programmed by astrocytes? Neuron. 2014;81:961-3.

106. Yang SH, Lee DK, Shin J, Lee S, Baek S, Kim J, et al. Nec-1 alleviates cognitive impairment with reduction of Abeta and tau abnormalities in APP/PS1 mice. EMBO Mol Med. 2017;9:61-77.

107. Qinli Z, Meiqing L, Xia J, Li X, Weili G, Xiuliang J, et al. Necrostatin-1 inhibits the degeneration of neural cells induced by aluminum exposure. Restor Neurol Neurosci. 2013;31:543-55.

108. lannielli A, Bido S, Folladori L, Segnali A, Cancellieri C, Maresca A. et al. Pharmacological Inhibition of Necroptosis Protects from Dopaminergic Neuronal Cell Death in Parkinson's Disease Models. Cell Rep. 2018;22:2066-79.

\section{Ready to submit your research? Choose BMC and benefit from:}

- fast, convenient online submission

- thorough peer review by experienced researchers in your field

- rapid publication on acceptance

- support for research data, including large and complex data types

- gold Open Access which fosters wider collaboration and increased citations

- maximum visibility for your research: over $100 \mathrm{M}$ website views per year

At BMC, research is always in progress.

Learn more biomedcentral.com/submissions 